provide for both the examination of the skeletal material preserved in museums and anatomical collections and the measurement by trained observers of groups of the existing population all over the country. Arrangements will also be made for the reduction and digestion of the material when collected, and for its publication.

THE projected survey is an object which is deserving of strong public support. Not only will the results be of the greatest scientific importance, as they will fill a gap in our knowledge of the composition of the British people which is much to be deplored, but they will also afford data of great significance, and from some points of view essential, in the consideration of a number of social and medical problems. The survey will involve expenditure on instruments, travelling for purposes of observation and publication, towards which contributions are invited from the public in an appeal supported by, among other signatories, Lord Onslow, Lord Raglan, Lord Meston, Sir Richard Gregory, Sir Henry Wellcome and the Rev. Edwin Smith, president of the Royal Anthropological Institute. Contributions should be addressed to the Treasurer, Royal Anthropological Institute, 52 Upper Bedford Place, London, W.C.1.

\section{Expedition to New Guinea}

Prans for the exploration of the country in the neighbourhood of the Sepik River in the mandated territory of New Guinea, which have been in preparation for some time, are now approaching completion; and Mr. G. M. Dyott, the leader, will leave shortly with two other members of the expedition for Australia, where he will be joined at Sydney by Mr. H. L. Williams, the Australian anthropologist, who will complete the personnel of the party. For some time past, the exploration of the Sepik River country has been an object of ambition of anthropologists and geographers alike. The greater part of it is entirely unknown. Last year, Mr. E. W. P. Chinnery, in the course of an official tour of duty as Government anthropologist, penetrated to the eastern boundary of the unknown territory. He reached the summit of Mount Hagen, and in his reports records how from a lofty plateau there he was able to look out over this country.

Mr. ChINNERy came into touch with hitherto undescribed peoples having many remarkable features in their culture, who were still living in the stone age (see NATURE, 134, 328 ; 1934). In the account of his experience which he has since published, he describes signs of occupation in the unvisited tableland below, which point to a system of cultivation differing from anything previously recorded in New Guinea. Mr. Dyott's expedition, in addition to making a plane-table survey of the country traversed, will devote special attention to the culture of the peoples in the Sepik area. It is also hoped to obtain conclusive evidence of the existence of the so-called 'devil-pig', a cloven-footed graminivorous animal, of which Mr. Monckton, formerly a resident magistrate in New Guinea, claimed to have observed the tracks, but of which knowledge otherwise rests on the report of the Papuans. They fear it greatly. The expedition is supported by the Australian Commonwealth Government and the Royal Geographical Society. The collections which the expedition hopes to make will be divided between the Pitt Rivers Museum, Oxford, and certain institutions in Australia.

\section{Vertical Take-off with the Autogiro}

Seĩon dE LA Cierva, lecturing before the Royal Aeronautical Society on March 15, made the first public announcement of the fact that he has produced a type of his autogiro that has achieved direct lift off the ground without any forward run. This was shown by the exhibition of cinema films in which the machine was seen to rise without displacing chocks placed in front of the wheels. Combined with its already proved ability of alighting with a practically negligible run, this makes it possible to visualise aircraft of this type operating from aerodromes of much smaller area, and less carefully kept surface, than hitherto. Sea-going operations, either from rough water or ship decks, are also facilitated by the absence of the need of horizontal run.

THE combination of vertical lift followed by horizontal flight at the desired instant is attained by altering the pitch angle of the horizontal rotating lifting surfaces of the autogiro. These are set at the angle of no lift while the rotor is speeded up by a torque applied from the engine. When the speed of rotation is considerably greater than that necessary for normal horizontal flight, the rotating mechanism is declutched, and simultaneously the angle of the surfaces is set to that for high lift. Thus a lift in excess of the weight of the machine is created, and it rises. When this impulse is expended, the machine would normally begin to descend, but in the meantime the full engine power has been changed back to the normal airscrew, and a thrust sufficient for horizontal flight is operating. This takes charge and the machine continues in horizontal or normal climbing flight at the will of the pilot. The machine appears to leap only three or four feet in the films shown. Señor Cierva suggests that while jumps of the order of 60-100 ft. are theoretically possible without needing prohibitive accelerations, an initial height of about $20 \mathrm{ft}$. is all that practical considerations demand.

\section{Television}

THE recent publication of the report of the Postmaster-General's Committee on Television has aroused considerable interest in this subject not only among those technically interested in radio communication and broadcasting, but also among the general public, who now definitely envisage the prospect of being able to 'look' as well as 'listen'. This interest has naturally given rise to a demand for literature, both technical and popular, on the subject. During the past year or so, however, progress in the technique of television at both the transmitting and receiving end has been so rapid that most of the books at 